\title{
STIL/TAL1 Fusion Gene
}

National Cancer Institute

\section{Source}

National Cancer Institute. STILITAL1 Fusion Gene. NCI Thesaurus. Code C19918.

A fusion gene that results from a microdeletion on chromosome 1 in the vicinity of p32 which fuses the promoter region and exon 1 of the STIL gene to exon 3 of the TAL1 gene. This deletion is associated with aberrant expression of the T-cell acute lymphocytic leukemia protein 1 and T-cell acute lymphoblastic leukemia. 